\title{
Saneamento básico: aumentos tarifários para investimentos na melhoria e expansão do serviço
}

\author{
Diogo R. Coutinho'
}

A Consulente é a autarquia municipal responsável pelos serviços de coleta, tratamento e distribuição de água e de coleta e tratamento de esgoto no município de São Carlos, São Paulo. Tem seus serviços remunerados por tarifas, nos termos da Lei Municipal no $10.255 / 1989$ e alterações posteriores. Tais tarifas são fixadas, revistas e reajustadas por decretos do Poder Executivo.

A Consulente informa que tramita na Promotoria de Justiça do Município de São Carlos inquérito civil que questiona os reajustes e revisões das tarifas de água e esgoto praticadas no período de 2006 a 2008. Narra também que representação do Ministério Público que levou à instauração do inquérito civil se fundamenta no fato de que, na exposição de motivos para a revisão levada a efeito pelo Decreto Municipal no 327, de 27 de dezembro de 2005, foram considerados custos a serem cobertos pela tarifa de água e esgoto (i) os juros previstos no contrato de financiamento celebrado com instituição financeira, a Caixa Econômica Federal, para a construção de uma nova estação de tratamento de esgoto (a Estação de Tratamento de Esgoto Monjolinho) e (ii) a contrapartida financeira prevista no referido contrato de financiamento, pela qual o Município de São Carlos se compromete a financiar parte da Estação de Tratamento de Esgoto Monjolinho. Além disso, a representação ao Ministério Público questiona, nas planilhas tarifárias que respaldaram os aumentos realizados em 2006 e 2007, a inclusão de (iii) custos relativos ao aumento do quadro de pessoal, destinado a atender a nova estação de tratamento de esgoto.

\footnotetext{
${ }^{1}$ Professor associado da Faculdade de Direito da Universidade de São Paulo (USP).
} 
A Consulente informa que a Estação de Tratamento de Esgoto Monjolinho teve sua construção iniciada no exercício de 2006, entrando em operação ao final de 2008. Complementa que os trabalhos estão quase completos, restando algumas obras por terminar no bairro Cidade Aracy.

De forma sintética, o argumento no qual se apoia a representação é o de que os aumentos tarifários praticados em São Carlos, por incorporarem diferentes tipos de custos relativos à construção de infraestrutura de tratamento de esgoto nova e por estarem associados à prestação de um serviço ainda não oferecido seriam incompatíveis com o regime jurídico de tarifas públicas. Estas, diferentemente das taxas, não teriam natureza tributária e não são compulsórias - isto é, os serviços prestados com a cobrança de tarifas não seriam de fruição obrigatória por parte dos cidadãos que, por meio de uma relação contratual, podem ou não contratá-los e, fazendo-o, devem ser cobrados de forma individualizada. Disso decorreria que, diferentemente das taxas, as tarifas somente podem ser cobradas de usuários que efetivamente utilizem os serviços oferecidos.

A Consulente informa, por fim, que o Ministério Público propôs, em face da representação oferecida e dos argumentos jurídicos que a respaldam, a celebração de Termo de Ajustamento de Conduta (TAC), prevendo que os valores auferidos pela autarquia no período de 2006 a fevereiro de 2009, como decorrência da inclusão na planilha tarifária dos custos com o pagamento de juros e contrapartida da Estação de Tratamento de Esgoto Monjolinho, assim como dos custos relativos ao aumento do quadro de pessoal para atendê-la, sejam descontados da tarifa atualmente cobrada, devolvidos aos usuários ou, ainda, compensados mediante o congelamento da tarifa.

Em face disso, procurando esclarecer certos aspectos jurídicos relativos à tarifação de serviços de saneamento básico no município de São Carlos, a Consulente, por meio de seus procuradores, submete, para minha análise e parecer, a presente consulta, mediante a apresentação dos seguintes quesitos:

1. É possível a cobrança, na tarifa de serviço público, de investimento na melhoria e expansão do serviço antes de sua efetiva conclusão?

2. A construção de Estação de Tratamento de Esgoto enquadra-se como melhoria e expansão do serviço?

3. A inclusão, nas tarifas de água e esgoto, dos custos com o pagamento de juros e contrapartida da Estação de Tratamento de Esgoto Monjolinho, bem como com o aumento do quadro de pessoal para operá-la, antes da sua entrada em operação, é legal?

Respondo à consulta com base no parecer que segue. 


\section{O cenário atual do saneamento básico no Brasil e o município de São Carlos}

Como é bem sabido, há uma clara correlação, de um lado, entre a oferta de serviços de coleta, tratamento e distribuição de água e de coleta e tratamento de esgoto e, de outro, certos indicadores de saúde da população. No Brasil, um dos países mais desiguais do planeta, a despeito do aumento do investimento verificado nos últimos anos e dos avanços recentes na consolidação de um arcabouço jurídico e institucional, o cenário do saneamento básico é preocupante, especialmente quando se trata da coleta e, sobretudo, do tratamento do esgoto. ${ }^{2}$

Se no caso da distribuição de água números mais recentes do $\mathrm{IBGE}^{3}$ revelam ganhos de cobertura $(84,4 \%$ das residências atendidas em 2009 contra $83,9 \%$ em 2008), no caso da coleta e tratamento de esgoto o déficit se agravou. Embora, em números absolutos, tenha havido incremento das redes, ${ }^{4} \mathrm{o}$ aumento da oferta de infraestrutura não foi suficiente para acompanhar o avanço do número de domicílios, revela o IBGE. ${ }^{5} \mathrm{O}$ percentual de residências com rede coletora ou fossa séptica ligada à rede coletora caiu de 59,3\% do total em 2008 para 59,1\% em 2009. ${ }^{6}$ Trata-se de um percentual significativamente elevado, que se soma a outras carências e gargalos de investimento em infraestrutura que, por sua vez, se traduzem em indesejáveis obstáculos ao desenvolvimento. ${ }^{7}$

2 O ciclo básico das operações da indústria do saneamento inicia-se com a coleta de água bruta em reservatórios naturais ou construídos, passa pelas atividades de tratamento da água, distribuição aos pontos de consumo residenciais, industriais e outros, descarte em uma rede de esgotamento e tratamento do esgoto, terminando com a devolução da água tratada ao ciclo natural.

3 Cf., para as estatísticas neste tópico apresentadas, a Síntese dos indicadores sociais 2010, publicação do Instituto Brasileiro de Geografia e Estatística (IBGE).

4 A última Pnad (Pesquisa Nacional por Amostra de Domicílios) mostra que houve aumento no número de residências com fossa séptica ou rede coletora, passando de 34,1 milhões em 2008 para 34,6 milhões em 2009.

5 A proporção de domicílios urbanos aumentou de $81,2 \%$ para 84,8\% (cerca de 48,9 milhões de domicílios em números absolutos).

6 Dentre os domicílios sem serviço de esgotamento sanitário, 27,2\% se utilizam de fossa e 4,3\% se utilizam de outras formas de escoadouro (vala, direto para o rio, lago ou mar e outras).

7 Do ponto de vista econômico, é bem conhecida a relação entre investimentos em infraestrutura e seus efeitos sobre o crescimento da economia como um todo. Sabe-se que, de modo geral, esses investimentos aumentam a eficiência dos fatores de produção e oferecem suporte à expansão das atividades produtivas, viabilizando o crescimento do emprego e da renda. Diversas correntes do pensamento econômico apontam que a elevação do "estoque" de infraestrutura de um país gera ganhos de produtividade expressivos. 
A urgência da expansão dos serviços de saneamento no Brasil se justifica por diferentes aspectos. É bom lembrar, em primeiro lugar, que essa indústria é caracterizada por gerar fortes economias externas ou externalidades, que são tipos recorrentes de falhas de mercado. Externalidades, simplificadamente, referem-se aos impactos e custos de uma decisão econômica sobre aqueles que não tomaram tal decisão. Elas ocorrem quando os custos e efeitos sociais (positivos ou negativos) de determinada atividade econômica não estão inteiramente refletidos nos preços dos bens ou serviços por ela produzidos ou prestados.

As externalidades positivas geradas pelo saneamento verificam-se, principalmente, em relação à saúde pública e ao meio ambiente. No setor de saneamento (tal como ocorre com o campo da educação, também marcado por externalidades) os custos enfrentados para aumentar a oferta de redes de distribuição de água, coleta e tratamento de esgoto são mais do que compensados pelos benefícios que geram, uma vez realizados, no médio e no longo prazos. Disso decorre a constatação da existência de uma falha de mercado, uma vez que, sem a intervenção do poder público voltada para assegurar a oferta desses serviços nos níveis socialmente desejáveis, os mercados tendem a não fazê-lo.

Exatamente por conta disso é que os serviços de saneamento básico, como regra, são prestados pelo poder público, seja diretamente por autarquias municipais, como no caso do município de São Carlos, seja sob a forma de concessões de serviço público, a depender do contexto. Em qualquer dos casos, a prestação de tais serviços precisa sempre ser objeto de um adequado esforço de planejamento, isto é, de uma articulação racional de meios e de fins.

Sobretudo em contextos de urbanização ou industrialização aceleradas, a ausência de planejamento setorial adequado para o saneamento acarreta efeitos sociais e custos de diversos tipos, como a degradação ambiental e a proliferação de doenças de veiculação hídrica. Assim, pode-se dizer que o planejamento da oferta de serviços de distribuição de água, coleta e tratamento de esgoto (bem como das atividades conexas de tratamento de resíduos sólidos, drenagem, vigilância sanitária, além da gestão de recursos hídricos por meio da administração de bacias hidrográficas) é uma atividade irrenunciável do poder público e também que a ausência desse planejamento que, de resto, é uma obrigação prevista em lei federal ${ }^{8}$, acarreta uma série de externalidades negativas.

8 Cf. o art. 19 da Lei no 11.445/2007. 
Com relação às externalidades negativas, pode-se dizer que, em países com rede pública de saúde como o Brasil, a falta de redes de saneamento e, em especial, de estações de tratamento de esgoto - gera custos elevados e em muitos casos incomensuráveis. Como se sabe, a água poluída é fonte de diversas doenças, como cólera, disenteria, febre tifoide, gastroenterite, diarreia infantil, leptospirose e esquistossomose. Por causa delas, os cofres públicos são constantemente onerados para arcar com tratamentos que seriam evitados se houvesse universalização do acesso ao saneamento. ${ }^{9}$

Além dos casos envolvendo a saúde pública, há também externalidades negativas quanto ao meio ambiente, uma vez que a operação de um sistema de saneamento supõe que a água bruta coletada deva ser tratada, distribuída de forma capilarizada até os pontos de consumo e, no seu retorno, ser submetia a tratamento de forma que possa completar o ciclo natural sem causar danos ao meio ambiente. Quando esse ciclo é interrompido em alguma de suas etapas intermediárias, a fase de tratamento do esgoto costuma ser sacrificada, com a produção de custos e prejuízos para toda a coletividade.

Como se viu, grande parte dos sistemas de saneamento em operação no Brasil não chega a executar as etapas finais, referentes ao tratamento e à devolução da água em condições adequadas ao ciclo natural. E vale a pena, nesse contexto, sublinhar que mesmo que haja coleta de esgoto, não é certo que ele seja tratado adequadamente. Isso significa, em outras palavras, que as etapas de coleta e tratamento de esgoto não se confundem: enquanto no país apenas metade da população é atendida no que diz respeito à coleta de esgotos, somente a reduzida parcela de $34,6 \%$ desse esgoto é tratada. ${ }^{10}$

No longo prazo, o despejo de esgoto in natura faz com que os custos e perdas de bem-estar social sejam multiplicados, indo, seguramente, mais além do custo de tratamento do esgoto. Novamente aqui se justifica a ação do poder público no sentido de minimizar tais externalidades negativas por meio da ação planejadora, executiva e reguladora do setor de saneamento básico, bem como pela expansão da infraestrutura de suporte à etapa de tratamento.

A cidade de São Carlos está, como se sabe, localizada na bacia hidrográfica do rio Tietê e por ela corre o rio Monjolinho, ${ }^{11}$ afluente do rio Jacaré-Guaçú.

9 Estima-se, por exemplo, que a universalização da rede de esgoto no país representaria uma economia de R\$ 745 milhões em gastos de internação no SUS ao longo dos anos. Ver o estudo Benefícios econômicos da expansão do saneamento básico brasileiro, produzido em 2010 pela Fundação Getulio Vargas com o Instituto Trata Brasil (p. 18).

10 Ver o estudo Benefícios econômicos da expansão do saneamento básico brasileiro, cit., p. 6.

11 O rio Monjolinho tem duas nascentes no município de São Carlos e até a entrada em funcionamento da estação de tratamento Monjolinho vinha sendo objeto de constante depósito de esgoto industrial e doméstico da cidade. 
Dado que o ponto mais elevado da bacia hidrográfica, com cerca de 800 metros, está em São Carlos e que há nessa área diversas nascentes que alimentam vários municípios de toda a região central do estado, é imprescindível que haja permanentes medidas para evitar a contaminação de sua bacia e pelo despejo de resíduos in natura e, com isso, como se diz no jargão econômico, "internalizar" externalidades. ${ }^{12}$

Essa conclusão é resultado de discussões que ocorrem em São Carlos pelo menos desde 1995, ano em que a realização de um laudo pericial apontou que o tratamento do esgoto era urgente nessa cidade. Ao tomar ciência desse laudo, o Saae apresentou um projeto de estação de tratamento de esgoto e uma Ação Civil Pública (ACP) versando sobre o tratamento do esgoto na cidade foi proposta em 1996. A partir de 1997, já durante o curso da ação, foi construído e paulatinamente sedimentado o entendimento entre as instituições e atores envolvidos na gestão dos recursos hídricos e do tratamento de esgoto em São Carlos. Como resultado desse diálogo institucional gerou-se um consenso que levou a Promotoria de Justiça do Meio Ambiente a solicitar, em 2001, a suspensão da ACP. A promotoria alegou, àquela altura, que um acordo seria mais salutar que estender os debates no Judiciário. Foi privilegiada, portanto, a construção coletiva de um arranjo adequado para o problema do tratamento do esgoto e dos recursos hídricos da região.

Soluções técnicas foram exaustivamente discutidas entre Cetesb, a Prefeitura Municipal, representada pelo Saae, e a própria Promotoria. Em 2003, um Termo de Ajustamento de Conduta (TAC) foi firmado, contemplando um projeto do sistema de tratamento de esgoto sanitário e o cronograma de execução das respectivas obras. Assim surgiram as condições para a construção, entendida como imperativa, da Estação de Tratamento de Esgoto Monjolinho. ${ }^{13}$

Feita essa contextualização sobre o panorama do saneamento básico no Brasil (em especial o problemático caso do tratamento do esgoto) e sobre o contexto fático no qual se deu a construção da Estação de Tratamento de Esgoto

12 “O município de São Carlos situa-se em região de rede hidrográfica abundante, sobre o divisor de águas das bacias dos rios Tietê e Mogi-Guaçu, destacando-se também a bacia do JacaréGuaçu, afluente do Tietê (...). O rio Tietê, pertencente à Região Hidrográfica do rio Paraná, localiza-se na área de maior concentração populacional da Região Hidrográfica, passando inclusive pela capital do Estado, a cidade de São Paulo. Em São Carlos, a maioria dos cursos d'água tem suas nascentes nas divisas da Comarca, daí a importância da gestão adequada dos recursos hídricos". Cf. DE MIO et al. A construção de consenso para gestão de recursos hídricos na cidade de São Carlos, SP, e distritos. Revista Minerva, v. 3, p. 161, 2006.

13 Cf. DE MIO et al. A construção de consenso para gestão de recursos hídricos na cidade de São Carlos, SP, e distritos, cit., p. 163. A estação entrou em funcionamento em dezembro de 2008. 
Monjolinho em São Carlos, será necessário enfrentar os aspectos jurídicos envolvidos - em especial, o argumento segundo o qual, para financiar a construção dessa imprescindível estação de tratamento, não poderiam ter sido incorporados à tarifa os custos decorrentes do pagamento de juros, contrapartida e contratação de pessoal, como visto acima.

Isso será feito em duas partes: no próximo tópico, apresento os fundamentos gerais da prestação de serviços públicos e de política tarifária (tópico 2) e, posteriormente, o caso de São Carlos será, em específico, discutido (tópico 3).

\section{Serviço público e política tarifária}

Costuma-se afirmar, com referência direta ao artigo 175 da Constituição Federal, que o serviço público pode ser prestado diretamente pelo Estado ou mediante concessão ou permissão a uma empresa privada. No caso do saneamento básico, como se verá, nos termos de suas diretrizes nacionais (Lei 11.445/2007 e Decreto 7.217/2010), é ainda mais ampla a chamada discricionariedade organizativa ${ }^{14}$ da administração pública. ${ }^{15} \mathrm{~A}$ primeira opção de prestação de serviço é por meio de órgão da administração direta ou por autarquia, empresa pública ou sociedade de economia mista que integre a administração indireta.

A segunda opção pode ocorrer mediante concessão ou permissão, não somente para delegação a empresas privadas, mas também para delegação a empresas estatais de ente federativo distinto do ente titular do serviço. Uma outra possibilidade ainda é, no âmbito de gestão associada de serviços públicos, a prestação do serviço de forma contratada, mediante contrato de programa autorizado por contrato de consórcio público ou por convênio

14 SILVA,José Afonso da. Comentário contextual à Constituição. 4. ed. São Paulo, Malheiros, 2007. p. 725.

15 "Saneamento básico", agora de acordo com a definição legal, é um conjunto de serviços, infraestruturas e instalações operacionais de (i) abastecimento de água potável, (ii) esgotamento sanitário, (iii) limpeza urbana e manejo de resíduos sólidos e (iv) drenagem e manejo de águas pluviais urbanas. Cada um desses serviços tem várias etapas. O esgotamento sanitário, analisado na presente consulta, compõe-se de (a) coleta, (b) transporte, (c) tratamento e (d) disposição adequados dos esgotos sanitários desde as ligações prediais até o lançamento final no meio ambiente. Assim, a construção de uma estação de tratamento de esgoto significa a complementação e/ou expansão de uma das etapas de um serviço de esgotamento sanitário já existente, não podendo ser considerado um serviço público autônomo novo (ver Lei 11.445/2007, art. 3ㅇ, I). 
de cooperação entre entes federados. Por fim, é igualmente possível que o serviço de saneamento básico seja prestado mediante autorização a usuários organizados em cooperativas ou associações, desde que os serviços se limitem a determinado condomínio ou a localidade de pequeno porte, predominantemente ocupada por população de baixa renda, onde outras formas de prestação apresentem custos de operação e manutenção incompatíveis com a capacidade de pagamento dos usuários. ${ }^{16}$

Esse amplo leque de arranjos institucionais e de atores implica distintos regimes jurídicos. Na prestação por concessão ou permissão, há, de acordo com Constituição, a figura do contrato, em torno do qual se construiu toda uma doutrina sobre equilíbrio econômico-financeiro e política tarifária.

No caso da prestação direta, embora a forma jurídica não seja contratual, não deve ser descartada uma política tarifária que também tenha em vista a sustentabilidade econômico-financeira da operação. Em outras palavras, mesmo quando decida prestar diretamente o serviço de saneamento básico, o Estado deve, de acordo com as diretrizes nacionais do setor, ter em vista uma remuneração do serviço que permita recuperação dos custos incorridos, prestados em regime de eficiência, bem como a geração dos recursos necessários para os investimentos (Lei 11.445/2007, art. 29, V e III, respectivamente). A antiga Lei 6.528/78, revogada pela Lei 11.445/2007, já determinava que a fixação tarifária deveria levar em conta "a viabilidade do equilíbrio econômicofinanceiro das companhias estaduais de saneamento básico e a preservação dos aspectos sociais dos respectivos serviços, de forma a assegurar o adequado atendimento dos usuários de menor consumo, com base em tarifa mínima" (art. 4º ).

Deve-se ainda registrar que o advento da Lei de Responsabilidade Fiscal (Lei Complementar 101/2000), aplicável à administração pública indireta, levou a gestão orçamentária pública a um outro patamar, exigindo planejamento e transparência, para prevenção de riscos e correção de desvios que possam afetar o equilíbrio das contas públicas (art. 1ำ $\S 1^{\circ}$ ). Essa Lei prescreve o cumprimento de metas e resultados entre receitas e despesas.

Em síntese, dito de outro modo, em consonância com o princípio da eficiência da administração pública, introduzido na Constituição (art. 37, caput) pela Emenda 19/1998, o macrorregime jurídico do serviço de saneamento básico preconiza uma operação que não seja ineficiente nem deficitária. Isso

16 Ver Lei 11.445/2007, art. 10. 
significa que a prestação direta do serviço público de saneamento básico pelo ente federativo titular do serviço deve contemplar uma política tarifária transparente e responsável, de forma planejada.

Planejamento implica a racionalização dos recursos por meio de estimativas tecnicamente bem fundamentadas da demanda pelo serviço e de outros custos decorrentes das diretrizes nacionais e de exigências legais, como, por exemplo, aquelas de natureza ambiental. Isso inclui a realização de obras necessárias à complementação e expansão da infraestrutura e das instalações operacionais de saneamento básico, atendendo aos objetivos de universalização e de continuidade do serviço. Na busca da adequação entre meios e fins, o planejamento inclui ainda a atualização do quadro de pessoal - incremento quantitativo (contratação) e qualitativo (treinamento, qualificação) do corpo de funcionários, de acordo com a expectativa de novas demandas, tecnologias e rotinas operacionais.

A esta racionalidade operacional da gestão do serviço deve corresponder uma racionalidade orçamentária. Eficiência e transparência tornaram-se imperativos da boa gestão pública, que abrange a prestação direta de saneamento básico pelo ente federativo titular do serviço. Assim, de acordo com os princípios e regras que regem o saneamento básico no Brasil, não é dada ao Estado a opção de conduzir de forma deficitária nem improvisada a prestação do serviço quando ela se dá por meio de entidades da administração indireta, como autarquias e empresas estatais. Além de operacionalmente irracional e fiscalmente irresponsável, tal opção afronta o ideal de transparência da atuação estatal, transferindo para o orçamento público geral um eventual "rombo" financeiro que é setorial, ou seja, que deveria ser suportado pela gestão sustentável dos serviços de saneamento.

Assim, torna-se imperativo que a entidade responsável pela prestação do serviço se paute pela busca da sua sustentabilidade e de seu equilíbrio econômico-financeiro em regime de eficiência. É essa diretriz que deve orientar a formulação do sistema de cobrança e composição de tarifas, de reajustes e de revisões tarifárias, e da política de subsídios.

Não se contratam pessoas qualificadas da noite para o dia, da mesma forma que não se complementam nem se expandem a infraestrutura e as instalações operacionais de forma abrupta. Para evitar essas situações, que implicariam alto risco operacional - continuidade do serviço - e considerável risco de desequilíbrio econômico-financeiro, torna-se necessário, num contexto de planejamento, que se inicie no presente a contratação e o treinamento de pessoal necessário para o futuro próximo. Da mesma forma, 
a dimensão econômico-financeira do planejamento inclui a estratégia de financiamento das novas estruturas, ou seja, a busca de crédito - quando necessário - para o investimento, o que exige, na prática, assumir encargos financeiros e contrapartidas.

O que se impõe, portanto, à administração pública na prestação direta do serviço de saneamento básico, insista-se, é que torne o serviço economicamente sustentável, ou seja, que a política tarifária seja realista, o que significa que ela deve ser capaz de cobrir não somente os custos incorridos, mas também os investimentos futuros necessários para a universalização e para a continuidade do serviço. Trata-se de imposição legal, e não de mera opção do administrador público.

Assim, incorporar à tarifa a recuperação dos custos reais incorridos e os investimentos futuros necessários - inclusive encargos financeiros - para a execução do planejamento não somente é autorizado por lei, mas constitui a própria diretriz legal. Não é dada à administração pública outra opção. Se o lucro não é o objetivo principal da prestação direta de serviço público pelo Estado, tampouco o déficit sistemático pode continuar sendo uma política social deliberada, como às vezes ocorreu no país.

Não pode ser aceito, por isso, o argumento segundo o qual a cobrança do usuário pelo serviço pelo custo real deste - ou seja, a prestação do serviço em regime de eficiência - seria contrária à finalidade social própria à prestação direta, já que a transferência integral do complexo e caro serviço de saneamento para a população tornaria a tarifa muito cara e, consequentemente, antissocial. Isso porque, uma vez estabelecida a fixação realista, racional e transparente da tarifa, como uma política geral responsável, a legislação autoriza, também, a cobrança de valores menores daqueles que não podem pagar a tarifa normal: "Poderão ser adotados subsídios tarifários e não tarifários para os usuários e localidades que não tenham capacidade de pagamento ou escala econômica suficiente para cobrir o custo integral dos serviços" (Lei $11.445 / 2007$, art. $29, \S 2$ o).

É oportuno, neste ponto, lembrar que as diretrizes nacionais sobre saneamento básico são estabelecidas em função da competência da União, nos termos da Constituição Federal:

Art. 21. Compete à União:

$(\ldots)$

$X X$ - instituir diretrizes para o desenvolvimento urbano, inclusive habitação, saneamento básico e transportes urbanos 
Portanto, embora o município de São Carlos possa ser considerado o titular do serviço de saneamento, toda legislação e toda regulação devem se harmonizar com as diretrizes nacionais. Estas, por sua vez, já eram claras no sentido de se viabilizar o equilíbrio econômico-financeiro das companhias estaduais de saneamento básico (Lei 6.528/1978, art. 4º), e se tornaram ainda mais claras (atual Lei 11.445/2007, que revogou a Lei 6.528/1978) no sentido de que mesmo a prestação do serviço por órgão da administração indireta, em qualquer nível federativo, deve ser sustentável, eficiente, transparente e racional, incorporando às suas tarifas os custos reais incorridos e as necessidades de investimentos futuros de acordo com um planejamento acrescentando-se a isso, como já referido, a necessidade de respeito à Lei de Responsabilidade Fiscal e à legislação ambiental.

Poder-se-ia objetar, no que se refere ao objeto da presente consulta, que, anteriormente à Lei 11.445/2007, inexistiam para os entes públicos municipais tais exigências de racionalidade, eficiência e sustentabilidade que hoje expressamente fazem parte das diretrizes legais nacionais do saneamento básico. Como consequência disso, os entes da administração indireta dos municípios poderiam ou deveriam praticar tarifas que não refletissem os custos reais da operação, já que a Lei 6.520/1978, ao exigir que a fixação tarifária levasse em conta o equilíbrio econômico-financeiro, fazia menção expressa apenas às companhias estaduais de saneamento (art. $4^{\stackrel{o}{o}) .{ }^{17}}$

Essa interpretação é equivocada, na medida em que nos levaria à conclusão de que conviveriam, no país, dois regimes jurídicos distintos para a política tarifária do serviço de saneamento prestados por entes públicos: no nível federativo estadual, a regra seria a do equilíbrio econômico-financeiro, da operação sustentável, coberta por tarifas que refletissem o custo real; na esfera municipal, a total liberação para operações deficitárias a serem cobertas pelo orçamento público, já que as tarifas não seriam realistas. Não seria cabível, obviamente, tal discrepância na condução do serviço público de saneamento com base exclusivamente no critério federativo.

Se o ente público estadual - companhias estaduais de saneamento poderia e deveria praticar tarifas realistas, ou seja, uma política tarifária sustentável, com vistas ao equilíbrio econômico-financeiro da operação, também

17 Lei 6.528/2007, art. 4ㅇ: “A fixação tarifária levará em conta a viabilidade do equilíbrio econômico-financeiro das companhias estaduais de saneamento básico e a preservação dos aspectos sociais dos respectivos serviços, de forma a assegurar o adequado atendimento dos usuários de menor consumo, com base em tarifa mínima". 
as autarquias, empresas públicas e sociedades de economia mista municipais, por analogia - considerando-se a omissão legal - , poderiam e deveriam seguir o mesmíssimo regime para o mesmo serviço público. Admitir o contrário, insista-se, seria conclusão absurda que levaria a discriminação insustentável para o federalismo brasileiro. ${ }^{18}$

Sobre a política tarifária dos serviços públicos cumpre ainda registrar o entendimento do Supremo Tribunal Federal (STF) no julgamento do polêmico caso do "Apagão" ocorrido durante o governo do presidente Fernando Henrique Cardoso, quando foram criados, em meio à crise energética, novos encargos para o usuário do serviço, um adicional tarifário específico para garantir a oferta de energia, ou seja, a continuidade do serviço público.

Em decisão unânime, o STF, além de entender que tais encargos não configuravam tributo (taxa), já que não se caracterizavam como prestação compulsória a ser integrada ao orçamento público nem a um fundo especial, mas sim autêntica tarifa ou preço público, argumentou que a política tarifária abrange não somente a continuidade, mas também a expansão de um serviço público. Em voto fartamente elogiado por seus pares, o relator, ministro Ricardo Lewandowski, afirmou o seguinte:

Segundo é possível concluir da Exposição de Motivos que acompanhou a MP 14/01, convertida na Lei 10.438/02, e do próprio texto desses diplomas normativos, as ações financiadas com a receita decorrente desses encargos tiveram como escopo assegurar o aumento da capacidade de geração e oferta de energia elétrica, bem como evitar interrupções abruptas em seu fornecimento, além de garantir o pleno atendimento da demanda.

Forçoso é convir, também, que tais encargos representavam uma contraprestação pecuniária pelo consumo de energia elétrica advinda do Sistema Interligado Nacional, além de constituir um meio para custear a continuidade da prestação do serviço.

18 Parece-me, neste ponto, que a reductio ad absurdum é mais do que suficiente para refutar a tese segundo a qual somente após a Lei 11.445/2007 é que entidades da administração pública municipal estariam enquadradas no regime de equilíbrio econômico-financeiro, ao prestar serviço público de saneamento básico. Sobre a reductio ad absurdum (ou argumento $a b$ absurdum), ver FERRAZ JUNIOR, Tercio Sampaio. Introdução ao estudo do direito: técnica, decisão, dominação. 6. ed. São Paulo, Atlas, 2010. p. 311-312. 
E não há nenhuma novidade nisso. Recordo que esta Suprema Corte já decidiu que as despesas destinadas a assegurar a continuidade, melhoria e expansão de um serviço público integram o preço público destinado a remunerá-lo. (R.E. 541.511-2/RS, p. 1199-1200, grifos meus) ${ }^{19}$

De forma bastante clara, portanto, o plenário do STF reconheceu (i) que a expansão de um serviço público pode ser precificada por uma determinada política tarifária, e que (ii) configura tarifa, e não tributo, essa componente adicional da prestação cobrada do usuário para a finalidade de ampliar a oferta do serviço.

Poder-se-ia eventualmente objetar que o entendimento jurisprudencial supra não se aplica ao setor de saneamento, porque água e esgoto seriam, supostamente, remunerados por taxa, ou seja, tributo, e não por tarifa. Entretanto, o próprio STF já decidiu reiteradas vezes sobre esta questão. A título de exemplo, basta consultar o R.E.-E.D. 447.536-7/SC (28/06/2005), relatado pelo min. Carlos Velloso (grifos meus):

EMENTA: Embargos de declaração opostos à decisão do Relator: conversão em agravo regimental. Constitucional. Tributário: taxa de esgoto sanitário. Prestação de serviço por concessionária. Natureza jurídica de preço público.

I - Embargos de declaração opostos à decisão singular do Relator. Conversão dos embargos em agravo regimental.

II - A jurisprudência do Supremo Tribunal Federal é no sentido de que não se trata de tributo, mas de preço público, a cobrança a título de água e esgoto. Precedentes.

III - Embargos de declaração convertidos em agravo regimental. Não provimento deste. ${ }^{20}$

19 Ao afirmar que esse não é um entendimento inédito no STF, o ministro relator referiu-se a dois importantes precedentes: o R.E. 117/315/RS, rel. Min. Moreira Alves, e a ADC 9/DF, rel. para o acórdão min. Ellen Gracie.

20 O acórdão cita vários precedentes. De conteúdo idêntico é a decisão no Edcl no RE 456.048/ SC, também relatado pelo min. Velloso. No mesmo sentido são as decisões mais recentes, monocráticas, como, por exemplo, dentre várias outras: RE 484.692/MS, rel. min. Eros Grau, RE 488.200/MS, rel. min. Eros Grau - nesta última decisão, ocorrida em 13-9-2006, o ministro relator afirma que a "jurisprudência do Supremo está consolidada no entendimento de que a remuneração pela prestação do serviço de fornecimento de água e coleta de esgoto não tem caráter de tributo, mas de preço público". 
Como se não bastasse o entendimento consolidado da mais alta corte do país, cumpre ainda registrar que tal matéria já se encontra bastante madura no direito brasileiro, já tendo ingressado, inclusive, expressamente, nas diretrizes legais nacionais sobre saneamento básico (Lei 11.445/2007, grifos meus):

\section{CAPÍTULO VI}

\section{DOS ASPECTOS ECONÔMICOS E SOCIAIS}

Art. 29. Os serviços públicos de saneamento básico terão a sustentabilidade econômico-financeira assegurada, sempre que possível, mediante remuneração pela cobrança dos serviços:

I - de abastecimento de água e esgotamento sanitário: preferencialmente na forma de tarifas e outros preços públicos, que poderão ser estabelecidos para cada um dos serviços ou para ambos conjuntamente; II - de limpeza urbana e manejo de resíduos sólidos urbanos: taxas ou tarifas e outros preços públicos, em conformidade com o regime de prestação do serviço ou de suas atividades;

III - de manejo de águas pluviais urbanas: na forma de tributos, inclusive taxas, em conformidade com o regime de prestação do serviço ou de suas atividades.

(...)

Art. 31. Os subsídios necessários ao atendimento de usuários e localidades de baixa renda serão, dependendo das características dos beneficiários e da origem dos recursos:

I - diretos, quando destinados a usuários determinados, ou indiretos, quando destinados ao prestador dos serviços;

II - tarifários, quando integrarem a estrutura tarifária, ou fiscais, quando decorrerem da alocação de recursos orçamentários, inclusive por meio de subvenções;

III - internos a cada titular ou entre localidades, nas hipóteses de gestão associada e de prestação regional.

As diretrizes legais nacionais, que sistematizaram o tratamento jurídico do saneamento básico, deixaram muito clara a distinção entre serviços de saneamento financiados pelo sistema tributário (taxas) e aqueles financiados preferencialmente por tarifas. A sistemática legal é coerente ao completar que os subsídios para os usuários de baixa renda serão tarifários, quando integrarem a estrutura tarifária, ou fiscais, quando decorrerem de recursos 
orçamentários. A Lei 11.445/2007 sistematiza, assim, a transparência que já deveria existir na gestão dos serviços públicos, evitando a confusão entre política tarifária e orçamento público.

A Lei Municipal de São Carlos, como se verá adiante, já havia feito sua opção pelo financiamento dos serviços de água e esgoto por meio de tarifa. As novas diretrizes legais, elaboradas nos termos da competência da União, vinculam todos os entes federativos. Por isso, no caso específico da presente consulta, a Lei 11.445/2007 só veio confirmar a opção anteriormente tomada.

\section{A prestação do serviço de saneamento básico no município de São Carlos}

Com já visto, os serviços de coleta, tratamento e distribuição de água e de coleta e tratamento de esgoto são, no município de São Carlos, prestados diretamente pelo poder público, por meio de uma autarquia municipal. A Consulente Saae, por seu turno, é remunerada pelos serviços que presta por meio de tarifas, como determina a legislação municipal. Refiro-me à disciplina criada pela Lei Municipal no 10.255 , promulgada pela Câmara Municipal em 28 de dezembro de $1989 .^{21}$

Depois de definir, em seu artigo 1ํㅡ o Saae como ente responsável pelos serviços de distribuição de água e coleta de esgoto e explicitar a adoção do mecanismo tarifário, a Lei Municipal no 10.255/1989 determina, em seu artigo 2․: "Artigo $2^{\circ}-\mathrm{O}$ custo por metro cúbico de água será calculado em função da produção, manutenção e administração do Serviço, bem como reservas para a recuperação de equipamentos e expansão do Serviço."

Veja-se aqui que a Lei Municipal no 10.255/1989, responsável pelo delineamento da política tarifária do município de São Carlos, expressamente autoriza que o prestador dos serviços de saneamento básico faça reservas para a recuperação de equipamentos e expansão do serviço de saneamento básico, em todas as suas fases. Isso significa que a norma jurídica contida nesse texto reconhece de forma clara que a tarifa de serviço público, como acima afirmado, deve assegurar ao operador dos serviços não apenas recursos para efetivamente prestá-lo, mas também para manter os equipamentos

${ }^{21}$ Essa lei foi posteriormente modificada pelas Leis no $10.955 / 1994,11.012 / 1995,11.906 / 1999$ e 14.258/2007. 
necessários para tanto, completá-lo e expandi-lo com vistas à universalização, sempre de forma planejada.

Por isso, pode-se desde logo concluir que não há, seja por conta da vigência do marco regulatório federal, seja por força da legislação municipal, razões que impeçam a que a cobrança de tarifas seja utilizada para provisionar custos futuros, relativos a investimentos que assegurem o funcionamento sistêmico e completo do setor de saneamento básico.

É preciso, por isso, dizer que o argumento segundo o qual a tarifa aplicada desde de 2006 em São Carlos cobrou por um serviço supostamente ainda inexistente - sendo, por isso, irregular - é equivocado. Com autorização legislativa inquestionável, o que o município de São Carlos fez foi, de forma financeiramente sustentável, reunir recursos para enfrentar o grave problema de despejamento de esgoto in natura nos rios, assim como procurou mitigar uma série de riscos de contaminação das bacias nas quais se situa.

Por que não cabe, neste caso, falar-se, no caso da construção da Estação de Tratamento de Esgoto Monjolinho, em "serviço inexistente"? Porque o que havia em São Carlos até a entrada em funcionamento dessa estação de tratamento era um serviço de saneamento básico existente, porém incompleto, uma vez que lhe faltava a etapa final de tratamento de esgoto para disposição final no meio ambiente. Por isso, não se pode dizer que a construção da Estação de Tratamento de Esgoto Monjolinho represente o momento em que passa a ser ofertado, de modo inédito, um serviço "independente" (de tratamento de esgoto) que não havia e que não faz parte da cadeia do saneamento. Ou seja: já havia saneamento básico em São Carlos quando da construção da Estação Monjolinho, embora não estivessem todas as suas fases e etapas cobertas por infraestrutura e pessoal capacitado. Disso decorreu a necessidade de expansão financiada pelas tarifas.

A adoção dessa visão sistêmica, não fragmentária, do setor refuta o argumento, também invocado, de que teria havido cobrança de usuários que não utilizaram efetivamente o serviço de tratamento de esgoto. Mais especificamente, rejeita a afirmação de que somente suportam os custos de construção da Estação de Tratamento de Monjolinho aqueles que fazem uso de água tratada, tendo sido "poupados" proprietários de lotes não interligados à rede pública.

Em primeiro lugar, deve-se ter em mente que os cidadãos que faziam uso de água tratada se beneficiaram da construção da Estação de Tratamento de Monjolinho porque passaram a viver em uma cidade com menos poluição e menos riscos de contaminação e doenças, capturando parte dos benefícios (externalidades positivas) que a estação de tratamento produz. 
Em segundo lugar, argumentos baseados em uma suposta discriminação de cidadãos não apenas ignoram a estrutura tarifária definida por lei em São Carlos (estrutura essa que, como se viu, permite, como norma de política tarifária, a formação de reservas), como ainda minimizam o objetivo de universalização do acesso ao serviço, que é um objetivo legítimo e defensável de política tarifária. Ao sugerirem que com os aumentos tarifários em tela foram criados dois grupos de contribuintes (o primeiro, que pagou pela estação de tratamento e o segundo, que não pagou), tais argumentos desconsideram que a expansão do saneamento ocorre justamente com a finalidade de incorporar os cidadãos ainda não beneficiados. ${ }^{22}$

A falha no argumento segundo o qual a criação de dois contingentes de contribuintes seria injusta reside, pois, na confusão feita entre o consumo individualizado de cada domicílio e a composição das tarifas de água e esgoto. Se por um lado é verdade que cada domicílio de São Carlos deva pagar apenas pelo seu consumo de água e utilização da rede de esgoto, de outro lado nada impede que o valor da tarifa seja aumentado para expandir a rede e promover sua universalização.

Tal fato, como é evidente, não faz com que os cidadãos paguem por serviços que eles não consumiram; o que ocorre é que eles passaram a pagar tarifas mais altas pelas mesmas quantidades consumidas - supondo-as constantes - por conta da necessidade de tratamento do esgoto de toda a cidade que, como visto antes, beneficia a todos e não apenas uma parcela dos cidadãos. Não há nada de injusto nisso.

Além de não haver na legislação nada que impeça a formação de reservas para investimento em expansão em São Carlos, ainda há o imperativo, constante do artigo $4^{\circ}$ da Lei Municipal em questão, de que o reajuste das tarifas deve assegurar ao Saae seu equilíbrio econômico financeiro. Veja-se:

Artigo 4ำ- O cálculo do custo do metro cúbico de água, para efeito de tarifação, terá por base o disposto no artigo $2^{\circ}$ desta Lei e será baixado

22 Vale notar que, como informa o site do Saae, a Estação de Tratamento Monjolinho terá sua capacidade de tratamento de esgoto aumentada com o passar do tempo. O projeto prevê ampliações para que a estação tenha capacidade para acompanhar o crescimento da cidade até pelo menos o ano de 2055 . Assim, inicialmente tratará $100 \%$ do esgoto gerado no município, com uma vazão de 600 litros por segundo (atualmente, são despejados no córrego do Monjolinho cerca de 500 litros por segundo). A segunda etapa deverá ser implantada em 2015, prevendo-se o tratamento de mil litros por segundo. Estimando uma população de $500 \mathrm{mil}$ habitantes (atualmente são pouco mais de $220 \mathrm{mil}$ ), a terceira etapa deverá ser implementada a partir de 2055 , com capacidade de tratar 1.270 litros por segundo. 
por Decreto Executivo, sendo reajustado mensalmente de acordo com o índice oficial da inflação do mês anterior, a fim de assegurar o equilíbrio econômico financeiro do SAAE.

Tal norma, na prática, impede que, ao se desincumbir de suas obrigações, o Saae o faça de modo a romper o equilíbrio de sua operação financeira, acumulando passivos e produzindo "rombos". Em outras palavras, não fosse por restrições fiscais previstas em legislação federal, o que se nota é que há, também no plano normativo municipal, limites claros à sobrecarga financeira da autarquia responsável pelo saneamento básico.

Todos os argumentos aqui apresentados levam à conclusão de que é muito difícil imaginar outra forma de arcar com os custos de uma obra imprescindível como é a Estação de Tratamento de Esgoto de Monjolinho que não aquela adotada a partir de 2006. Soluções financeiras deficitárias não são mais adequadas aos padrões de gestão pública eficiente e responsável, como já se argumentou, além de serem vedadas pelo novo marco regulatório federal do setor.

Ao mesmo tempo, como já afirmado, não havia qualquer restrição ou vedação legal ao aumento das tarifas. Vale notar, aliás, que o município de São Carlos, como informa a Consulente, jamais efetuara quaisquer reservas para recuperação de equipamentos ou expansão do serviço desde a entrada em vigor da Lei Municipal 10.255, de 1989. Como não havia um fundo destinado a tanto, foi necessário, a partir de 2006, reunir recursos para a obra, que teria de ocorrer cedo ou tarde..$^{23}$

\section{Conclusão}

Diante de todas as considerações feitas até este ponto, passo a responder de forma sucinta aos quesitos formulados pela Consulente:

1. É possível a cobrança, na tarifa de serviço público, de investimento na melhoria e expansão do serviço antes de sua efetiva conclusão?

23 Vale lembrar que o município de São Carlos ganhou um prêmio de aproximadamente R\$ 21 milhões, divididos em 12 parcelas trimestrais, em razão da construção da Estação de Tratamento de Esgoto Monjolinho. Este valor foi concedido pelo Programa de Despoluição de Bacias Hidrográficas (Prodes), criado em 2001 pela Agência Nacional de Águas (ANA). 
Sim. A política tarifária de um serviço público, como aliás reconhecido pelo Supremo Tribunal Federal, deve dar conta não somente de sua continuidade, mas também de sua melhoria e expansão. Repassar à tarifa os custos destas últimas somente após as conclusões das obras de infraestrutura e de instalações operacionais que levariam às referidas melhoria e expansão poderia colocar em risco a sustentabilidade do serviço em regime de eficiência, ou seja, seu equilíbrio econômico-financeiro. Defender o contrário seria alegar que a lei obriga o ente público municipal a operar de maneira deficitária em contextos de necessidade de melhoria e expansão, impedindo-o de praticar tarifas realistas com vistas ao seu planejamento, ao seu conjunto de metas e objetivos de curto, médio e longo prazo para a universalização do serviço. Não somente a Lei de Responsabilidade Fiscal, mas também o marco legislativo do setor de saneamento básico determinam que a gestão econômico-financeira do serviço deve ser equilibrada. A função social do serviço - ou seja, a prática de tarifas subsidiadas para os usuários de menor renda - deve ser garantida por outro mecanismo, o da política de subsídios elaborada em cima de uma política tarifária realista aplicável ao usuário comum. Além de tudo isso, a própria legislação municipal, que estipulou especificamente a política tarifária do serviço de saneamento de São Carlos, autoriza não somente a inclusão, na tarifa, dos custos passados e correntes, mas também dos investimentos necessários.

2. A construção de Estação de Tratamento de Esgoto enquadra-se como melhoria e expansão do serviço?

Sim. O tratamento de esgoto é uma etapa complementar necessária para o serviço de esgotamento sanitário, vindo se somar às atividades, infraestruturas e instalações operacionais de coleta e transporte dos esgotos sanitários. No caso em tela, configurava obra imprescindível para viabilizar a disposição final adequada dos esgotos no meio ambiente. Sendo caracterizada como melhoria e expansão do serviço de esgotamento sanitário, poderia ter o investimento necessário para a sua implementação incluído na política tarifária do serviço.

3. A inclusão, nas tarifas de água e esgoto, dos custos com o pagamento de juros e contrapartida da Estação de Tratamento de Esgoto Monjolinho, bem como com o aumento do quadro de pessoal para operá-la, antes da sua entrada em operação, élegal?

Sim. Como já adiantado na resposta ao item anterior, e exposto ao longo do parecer, ao planejamento operacional do serviço deve corresponder uma 
gestão econômico-financeira racional, sustentável e fiscalmente responsável, o que implica poder fazer refletir na tarifa os investimentos necessários para viabilizar a melhoria e a expansão do serviço. Como ocorre com qualquer empreendimento numa economia de mercado, inclusive no campo dos serviços públicos e sua complexa infraestrutura, o plano de investimentos pode ser total ou parcialmente viabilizado pelo crédito bancário, o que implica assumir encargos financeiros como juros, e contrapartidas. Da mesma forma, a melhoria e a expansão do serviço demandam mão de obra especializada e especificamente treinada para que o serviço seja oferecido com a devida qualidade. Esta contratação não pode ser feita de forma improvisada ou açodada, da noite para o dia, às vésperas da inauguração das novas instalações, o que seria temerário para o funcionamento adequado do serviço. Essa contratação pode e deve ser feita com a devida antecedência para que a operação das novas instalações seja viável logo após a conclusão das obras. Em síntese, contrair crédito, assumir encargos financeiros e contratar mão de obra antes da conclusão das obras de expansão do serviço público não somente são rotinas e providências autorizadas pela legislação, como constituem práticas corriqueiras de gestão de um serviço público num contexto de melhoria e expansão.

É o parecer.

São Paulo, 26 de novembro de 2010.

O conteúdo e as conclusões aqui apresentados são de exclusiva responsabilidade do autor e não refletem necessariamente as opiniões da Universidade de São Paulo. 